\title{
A uniformity trial on Indian mustard for determination of optimum size and shape of blocks
}

\author{
Mujahid Khan ${ }^{1 *}$, Ramesh Chander Hasija ${ }^{2}$, Des Raj Aneja ${ }^{3}$ and Manish Kumar Sharma ${ }^{4}$ \\ ${ }^{1}$ Department of Mathematics, Statistics and Physics, Chaudhary Charan Singh Haryana Agricultural University, \\ Hisar-125004 (Haryana), INDIA \\ ${ }^{2}$ Department of Mathematics, Statistics and Physics, Chaudhary Charan Singh Haryana Agricultural University, \\ Hisar-125004 (Haryana), INDIA \\ ${ }^{3}$ Department of Mathematics, Statistics and Physics, Chaudhary Charan Singh Haryana Agricultural University, \\ Hisar-125004 (Haryana), INDIA \\ ${ }^{4}$ Division of Statistics and Computer Science, Sher-e-Kashmir University of Agricultural Sciences and Technology, \\ Chatha, Jammu-180009 (J\&K), INDIA \\ *Corresponding author. E-mail: mkhanstat@gmail.com
}

Received: January 13, 2016; Revised received: June 03, 2016; Accepted: August 16, 2016

\begin{abstract}
The aim of this study was to estimate the optimum block size with the shape for field research experiments. A uniform crop of Indian mustard (Brassica juncea L.) variety RH-749 was raised during 2013-14 rabi season over an area of $48 \mathrm{~m} \times 48 \mathrm{~m}$ (2304 basic units) at Research Farm of Oilseed section, Department of Genetics and Plant Breeding, CCSHAU, Hisar, Haryana, India. The harvesting of crop was done in small units each of size $\mathrm{Im} \times$ Im $\left(1 \mathrm{~m}^{2}\right)$. The blocks of sizes 4, 6, 8, 12 and 24 plots with various shapes, for different plot sizes were considered. The coefficient of variation (CV) decreased from 10.66 to 3.89 with the increase in block size from 4 to $\underline{24}$, indicating that as the block size increased, homogeneity within the block also increases and the blocks elongated in E-W direction were more effective in reducing error variation than those elongated in N-S direction. It was also observed that C.V. without blocking (20.04) was much higher in comparison with the C.V. with blocking (3.89), thus indicating that blocking was beneficial in reducing error variation. The 24 plot blocks were found to be most efficient with $12 \mathrm{~m} \times$ $2 \mathrm{~m}$ block shape. Rectangular blocks are also advisable either when the experimenter does not have any idea about the fertility pattern of the experimental area or when border effects are large.
\end{abstract}

Keywords: Blocking, Efficiency, Optimum block size, Optimum block shape, Uniformity trial

\section{INTRODUCTION}

The conduct of cost-effective agricultural research facilitates the efficient use of limited resources; and with minimal cost, the research trials should attain an acceptable level of experimental precision. The size and shape of plots and blocks, and the number of replications used are the major factors that determine the cost of a field experiment, since these factors are directly proportional to the area occupied by the field trial (Taye et al., 2000).

In field experiments and for the most crops, the heterogeneity of the soil is always the first factor to be given attention, to increase the efficiency of the experiment and reliability of the result. This variability may be random or systematic. Usually researchers assume that the errors are independently, randomly distributed and use block experiments to minimize this source of variation. It is of utmost importance to use the most efficient shape, size and arrangements of blocks in a particular experiment for obtaining the reliable results. The precision of significance tests in field trials are largely controlled by size and shape of blocks, which are further controlled by the size and shape of plots available for the specific trial, the nature of fertility or other variation. The problem was therefore selected to see a scientific basis for using block size and shape within optimum limits. To cope with the problem of the researchers, it has become necessary to standardize a suitable block size and shape for the experimental plot of major crops grown under different conditions, which will reduce the standard error of the experiments (Masood and Raza, 2012).

The variability of the experimental area can be quantified by organizing uniformity trials specifically designed for identifying the variability or the heterogeneity index of the characteristic under study in the experimental area (Smith, 1938). In this methodology, data on the evaluated characteristic is collected from small plots, called as basic units, and these basic units are then amalgamated to form plots of different sizes $(\mathrm{X})$ in grouping together adjacent basic units. The number of plots of this size, the mean, variance and coefficient of variation $(\mathrm{CV})$ are calculated for each 
designed plot size. The plots are then arranged within blocks of different sizes and shapes to find out the optimum block size and shape (Storck et al., 2010).

Optimum block size and shape for yield have been estimated for several different crops, both agronomic and horticultural, by Agnihotri et al. (1995 and 1996), Handa et al. (1995), Masood and Javed (2003), Leilah and Al-Khateeb (2007), Lucas (2007), Kumar et al. (2008) and Storck et al. (2010).

As the Haryana state ranks 4th in the acreage, 2nd in the production and 2 nd in the productivity of the rapeseedmustard in India, it was of prime importance to conduct the uniformity trial on Indian mustard (Brassica juncea L.) in Haryana state of India with the utilization of data for the estimation of optimum block size and shape.

\section{MATERIALS AND METHODS}

Source of data: Indian mustard (Brassica juncea L.) cultivar RH-749 was grown using uniform crop improvement practices during rabi season of 2013-14 at Research Farm of Oilseed section, Department of Genetics and Plant Breeding, CCSHAU, Hisar, Haryana state, India, over an area of the $48 \mathrm{~m} \times 48 \mathrm{~m}\left(2304 \mathrm{~m}^{2}\right)$. The field was divided into rows (East-West direction) and columns (North-South direction). The units were arranged in 48 rows and 48 columns, each consisting of 48 units and harvesting of crop was done in small units each of size $1 \mathrm{~m} \times 1 \mathrm{~m}\left(1 \mathrm{~m}^{2}\right)$. The grains from each of these basic units were harvested, bagged, threshed, cleaned, dried and weighted (in grams) separately.

Statistical analysis: The contiguous units were combined by taking $1,2,3,4,6,8,12,24$ and 48 units along rows (E-W direction) and 1, 2, 3, 4, 6, 8, 12, 24 and 48 units across columns to form plots of different shapes and sizes. The plots were then grouped into blocks of 4, 6, 8, 12 and 24 plots. The C.V.'s for different block sizes were calculated by using the formula

$$
\text { C.V. }=\frac{\sqrt{\text { EMS }}}{\text { Mean }} \times 100
$$

Where, the error mean square (EMS) was obtained from analysis of variance tables for blocks of different plot sizes.

Relationship between C.V. and size of blocks: Smith (1938) gave an empirical relationship between plot size $(\mathrm{X})$ and plot variance $\mathrm{V}_{\mathrm{x}}$. The law states that

$$
\mathrm{V}_{\mathrm{x}}=\mathrm{V}_{1} / \mathrm{X}^{\mathrm{b}}
$$

which on $\log$ transformation becomes

$\log \mathrm{V}_{\mathrm{x}}=\log \mathrm{V}_{1}-\mathrm{b} \log \mathrm{X}$

Where,

$\mathrm{V}_{\mathrm{x}}$ is the variance of yield per unit area among plots of size $\mathrm{X}$ units,

$\mathrm{V}_{1}$ is the variance among plots of size unity,

$\mathrm{b}$ is the regression coefficient, indicating the relationship between adjacent individual experimental units or in other words it reflects soil heterogeneity and thus serve as an index of soil heterogeneity andX is the number of basic units per plot.

The index of soil heterogeneity (b) is the regression of the log of the plot variance (on a per unit basis) on the $\log$ of the number of basic units per plot. Generally, coefficient of variation is used as a relative measure for computing variability index of $\mathrm{V}_{\mathrm{x}}$.

In equation (2), b was computed by least square procedure and on solving the normal equations so obtained, we get

$$
\hat{b}=\frac{n \sum_{i=1}^{n} \log X_{i} \log V_{x_{i}}-\left(\sum_{i=1}^{n} \log V_{x_{i}}\right)\left(\sum_{i=1}^{n} \log X_{i}\right)}{n \sum_{i=1}^{n}\left(\log X_{i}\right)^{2}-\left(\sum_{i=1}^{n} \log X_{i}\right)^{2}}
$$

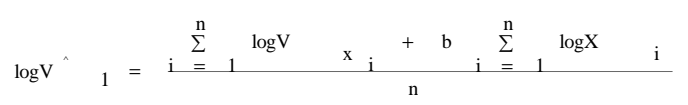

The value of regression coefficient, $b$, was computed for all the corresponding plot sizes to the blocks of 4, 6, 8, 12 and 24 plots. The coefficient of determination $\left(\mathrm{R}^{2}\right)$ was computed for all the block arrangements for the fitted equations to examine the suitability of the Smith's equation.

Block efficiency: Since experimental materiel was not homogeneous, it may be possible to stratify the material into homogeneous blocks. Thus stratification or blocking was one of the methods for controlling the variability. The improved precision of the estimates brought about by using blocking to reduce the experimental error, was expressed as block efficiency. The block efficiency may also be defined as the ratio of variance without blocking to the variance obtained with blocking. If $\mathrm{V}_{0}$ denotes the variance without blocking and $\mathrm{V}_{\mathrm{B}}$ denotes the variance with blocking, then the block efficiency (B.E.) may be worked out using the formula given by Agarwal and Deshpande (1967):

$$
\text { B.E. }=\frac{\mathrm{V}_{0}}{\mathrm{~V}_{\mathrm{B}}}
$$

As we have considered the blocks of varying sizes, i.e. 4 , $6,8.12$ and 24 , then the block efficiencies for the various block arrangements was worked out to find the suitable sizes and shapes of the blocks from these combinations.

\section{RESULTS AND DISCUSSION}

It was observed that the coefficient of variation decreases with the increase in the block size, indicating that as the size of block was increased; the homogeneity within the block also increases. In the experiment, the minimum C.V.'s for 4, 6, 8, 12 and 24 plot blocks, for the plots of size 1 unit were 10.66, 8.68, 7.93, 5.93 and 3.89 per cent, respectively. The same pattern of decreasing C.V. was observed for all other plot sizes. The decrease in the coefficient of variation varies with different block sizes; it was minimum for the largest block size. Thus, 24 plot blocks were more efficient 
Table 1. Coefficient of variation of various plot sizes for different block arrangements.

\begin{tabular}{cccccc}
\hline \multicolumn{7}{c}{ Coefficient of variation } \\
\hline Plot size & 4-plot block & 6-plot block & 8-plot block & 12-plot block & 24-plot block \\
\hline in units) & & & & & \\
\hline $\mathbf{1}$ & 10.66 & 8.68 & 7.93 & 5.93 & 3.89 \\
$\mathbf{2}$ & 7.93 & 5.93 & 5.25 & 4.53 & 2.89 \\
$\mathbf{3}$ & 5.93 & 6.14 & 3.89 & 2.89 & 2.01 \\
$\mathbf{4}$ & 5.25 & 3.89 & 4.37 & 3.01 & 2.25 \\
$\mathbf{6}$ & 3.89 & 3.52 & 2.89 & 2.53 & 1.81 \\
$\mathbf{8}$ & 4.37 & 2.89 & 3.41 & 2.25 & 1.77 \\
$\mathbf{1 2}$ & 2.89 & 3.01 & 2.53 & 1.02 & 1.02 \\
$\mathbf{2 4}$ & 2.53 & 2.25 & 1.81 & 1.32 & \\
$\mathbf{4 8}$ & 1.81 & 1.77 & & & 0.43 \\
\hline
\end{tabular}

Table 2. Coefficient of variation of various plot sizes for different block arrangements.

\begin{tabular}{ccccc}
\hline $\begin{array}{c}\text { Plot size } \\
\text { (in units) }\end{array}$ & Plot shape & Block size & Block shape & Minimum C.V. \\
\hline $\mathbf{1}$ & $1: 1$ & 24 & $1: 24$ & 3.89 \\
$\mathbf{2}$ & $1: 2$ & 24 & $1: 24$ & 2.89 \\
$\mathbf{3}$ & $1: 3$ & 24 & $3: 8$ & 3.01 \\
$\mathbf{4}$ & $1: 4$ & 24 & $1: 24$ & 2.53 \\
$\mathbf{6}$ & $1: 6$ & 24 & $3: 8$ & 2.25 \\
$\mathbf{8}$ & $1: 8$ & 24 & $4: 6$ & 1.81 \\
$\mathbf{1 2}$ & $1: 12$ & 24 & $6: 4$ & 1.77 \\
$\mathbf{2 4}$ & $1: 24$ & 24 & $12: 2$ & 1.02 \\
$\mathbf{4 8}$ & $1: 48$ & 24 & $12: 2$ & 0.43 \\
\hline
\end{tabular}

Table 3. Fairfield Smith's equation for different block arrangements.

\begin{tabular}{ccc}
\hline Type of arrangement & $\begin{array}{c}\text { Smith's equation } \\
\mathbf{V}_{\mathbf{X}}=\mathbf{V}_{\mathbf{1}} \mathbf{X}^{-\mathbf{b}}\end{array}$ & $\mathbf{R}^{\mathbf{2}}$ \\
\hline 4 plot block & $10.1675 \mathrm{X}^{-0.4572}$ & 0.8946 \\
6 plot block & $8.0075 \mathrm{X}^{-0.4104}$ & 0.9483 \\
8 plot block & $7.3485 \mathrm{X}^{-0.4403}$ & 0.9656 \\
12 plot block & $5.9744 \mathrm{X}^{-0.4188}$ & 0.9466 \\
24 plot block & $4.8764 \mathrm{X}^{-0.5221}$ & 0.9799 \\
\hline
\end{tabular}

than the other block sizes $4,6,8$ and 12 , for the given plot sizes.

It was also observed that C.V. without blocking was much higher in comparison with the C.V. with blocking, thus indicating that blocking was beneficial in reducing error variation.

Effect of block shape: For a given block size, generally, the blocks elongated along E-W direction had less C.V. as compared to the block elongated across N-S direction, for instances for a plot of size one unit, the C.V. for block size 4 with shapes 1:4 was 10.66 per cent which was less than the C.V. for the shape 4:1 i.e. 11.46. Thus there was reduction of 7 per cent in C.V. from shape $1: 4$ to $4: 1$. The reduction was large for bigger size of plots and blocks. For example for same plot size $1 \mathrm{~m}^{2}$ with block size 12 , the C.V. with block shape
1:12 was 5.93 per cent and it reduces by 20 per cent for block shape 6:2 i.e. 7.47 per cent and for block size 24 for the plot size $1 \mathrm{~m}^{2}$, the C.V. with block shape $1: 24$ was 3.89 per cent and it reduces by 35 per cent for block shape 6:4 i.e. 6.04 per cent. It was observed that the long and narrow blocks elongated in E-W direction were the most efficient ones.

Relationship between coefficient of variation and block size: The minimum coefficient of variation's were to be found out for all the combinations of plot sizes and shapes for different arrangements of blocks and are presented in Table 2. The further calculations should be carried out on these minimum coefficients of variation.

As we have earlier concluded that the 24 plot blocks were more significant than all the other blocks and for the 24 plot size, the most significant block shape was 12:2 i.e. 12 plots elongated along E-W direction and 2 plots elongated along N-W direction. So, as per the earlier findings regarding block size and block shape, and this result regarding minimum coefficient of variation for all the combinations of plot sizes, plot shapes, block sizes and block shapes, we have concluded that 24 plot blocks elongated in E-W direction (i.e. 12:2) was found to be optimum for the Indian mustard.

Fitting of Smith's equation: After examining empirically, the effect of size of blocks on error variability, a functional relationship between plot size and C.V. has 
Mujahid Khan et al. / J. Appl. \& Nat. Sci. 8 (3): 1589 - 1593 (2016)

Table 4. Coefficient of variation and block efficiency for various plots and block sizes.

\begin{tabular}{cccccccccccc}
\hline $\begin{array}{c}\text { Plot size } \\
\text { (in units) }\end{array}$ & $\begin{array}{c}\text { Without } \\
\text { Blocking } \\
\text { C.V. }\end{array}$ & \multicolumn{2}{c}{ 4-plot blocks } & \multicolumn{2}{c}{ 6-plot blocks } & \multicolumn{2}{c}{ 8-plot blocks } & \multicolumn{2}{c}{ 12 - plot blocks } & \multicolumn{2}{c}{ 24-plot blocks } \\
\cline { 2 - 12 } & C.V. & B.E. & C.V. & B.E. & C.V. & B.E. & C.V. & B.E. & C.V. & B.E. \\
\hline 1 & 20.07 & 10.66 & 1.88 & 8.68 & 2.31 & 7.93 & 2.53 & 5.93 & 3.38 & 3.89 & 5.15 \\
2 & 14.12 & 7.93 & 1.78 & 5.93 & 2.38 & 5.25 & 2.68 & 3.89 & 3.62 & 2.89 & 4.88 \\
3 & 11.81 & 5.93 & 1.99 & 6.14 & 1.92 & 3.89 & 3.03 & 4.53 & 2.60 & 3.01 & 3.92 \\
4 & 10.22 & 5.25 & 1.94 & 3.89 & 2.62 & 4.37 & 2.33 & 2.89 & 3.53 & 2.53 & 4.03 \\
6 & 8.24 & 3.89 & 2.11 & 3.52 & 2.34 & 2.89 & 2.85 & 3.01 & 2.73 & 2.25 & 3.66 \\
8 & 7.42 & 4.37 & 1.69 & 2.89 & 2.56 & 3.41 & 2.17 & 2.53 & 2.93 & 1.81 & 4.09 \\
12 & 5.44 & 2.89 & 1.88 & 3.01 & 1.80 & 2.53 & 2.15 & 2.25 & 2.41 & 1.77 & 3.07 \\
24 & 3.28 & 2.53 & 1.29 & 2.25 & 1.45 & 1.81 & 1.81 & 1.77 & 1.85 & 1.02 & 3.21 \\
48 & 1.44 & 1.81 & 0.79 & 1.77 & 0.81 & 1.32 & 1.09 & 1.02 & 1.41 & 0.43 & 3.34 \\
\hline
\end{tabular}

been fitted. The Smith (1938) relation between plot size $\mathrm{X}$ and coefficient of variation $\mathrm{V}_{\mathrm{X}}$ was found to be most suitable for all plot blocks and the results have been summarized in Table 3 .

The coefficients of determination $\left(\mathrm{R}^{2}\right)$ for various block arrangements of the Smith's equation vary from 0.8946 to 0.9799 when plot sizes were considered and the $\mathrm{R}^{2}$ was found to be maximum for the 24 plot blocks, so the 24 plot blocks were more efficient then all the other blocks. Also the index of soil variability (b) varies from 0.4104 to 0.5221 .

Block efficiency: Blocking was found to be useful for reducing experimental error from the plot yield by removing the portion of variability present in the plot and mak-ing the experimental field less heterogeneous. This advantage of using blocks was expressed as the block efficiency.

For the present uniformity trial data, we consider the blocks with 4, 6, 8, 12 and 24 plots for the various plot sizes. Then the block efficiencies for different plot arrangements within the blocks were calculated and presented in Table 4, along with respective coefficients of variation. This degree of effectiveness of blocks in increasing the accuracy of experiments was given by $\mathrm{V}_{0} /$ $V_{B}$, the ratio of the error variance obtained without blocking to the error variance obtained with blocking.

It was observed that the block efficiency generally increases with the increase in the block size, for the given size and shape of plots. Thus the 24 plots block was more efficient than $4,6,8$ and 12 plot blocks. There was no consistency in the effect of the shape of the blocks, so long as its size was the same. However, the coefficients of variation in case of blocking were less than those in without blocking, thus indicating the gain in efficiency due to grouping.

It can be concluded that the increase in the block size for a given plot size, leads to the increase in the block efficiency. Hence larger blocks were found to be more effective than the smaller blocks, in reducing the error variability.

\section{Conclusion}

The coefficient of variation decreased with the increase in the block size, indicating that as the size of block increased, the homogeneity within the block also increased. Thus, 24 plot blocks were more efficient than the other block sizes 4, 6, 8 and 12, for the given plot sizes. It was observed that the blocks elongated in E-W direction were more effective in reducing error variation than those elongated in N-S direction. It was also observed that C.V. without blocking was much higher in comparison with the C.V. with blocking, thus indicating that blocking was beneficial in reducing error variation. It was observed that the block efficiency generally increases with the increase in the block size, for the given size and shape of plots. The block size of $24 \mathrm{~m}^{2}$ with $12 \mathrm{~m} \times 2 \mathrm{~m}$ shape is recommended for future field experiments on Indian mustard yield trials.

\section{REFERENCES}

Agarwal, K.N. and Deshpande, M.R. (1967). Size and shape of plots and blocks in field experiments with dibbled paddy. Indian Journal of Agricultural Sciences. 37 (6) : 445-455.

Agnihotri, Y. and Agarwal, M.C. (1995). Uniformity trials for determination of optimum size and shape of plots/ blocks for experimentation with Acacia catechu. The Indian Forester. 121(8).

Agnihotri, Y., Agarwal, M.C. and Kumar, N. (1996). Size and shape of plots and blocks for field experiment with Eucalyptus in Shivalik Hills. Indian Jour. Forestry. 19 (1) : 74-78

Handa, D.P., Sreenath, P.R. and Rajpali, S.K. (1995). Uniformity trial with Lucerne grown for fodder. Grass and Forage Science. 50 (3) : 209-216.

Kumar, A., Pandey, V., Shekh, A.M., Dixit, S.K. and Kumar, M. (2008). Evaluation of crop soybean (Glycine max [L] Merrill) model under varying environmental condition. American-Eurasian Journal of Agronomy. 1 (2) : 
34-40.

Leilah, A.A. and Al-Khateeb, S.A. (2007). Convenient quadrat size, shape and number in the desert rangeland of Saudi Arabia. Pakistan Jour. Agric. Res. 20 : 62-70.

Lucas, L.G. (2007). Field plot techniques for cotton experiments. M. S. Thesis, University of Philippines, LosBaos.

Masood, M.A. and Javed, M.A. (2003). Variability in field experiments in maize crop in Pakistan. Pakistan J. Agric. Sci. Faisalabad. 40 (3-4) : 207-209.

Masood, M.A. and Raza, I. (2012). Estimation of optimum field plot size and shape in paddy yield trial. American-
Eurasian Journal of Scientific Research. 7 (6) : 264269.

Smith, H.F. (1938). An empirical law describing heterogeneity in the yields of agricultural crops. Journal of Agricultural Science. $28: 1-23$.

Storck, L., Filho, A.C., Lopes, S.J., Toebe, M. and de Silveira, T.R. (2010). Experimental plan for single, double and triple hybrid corn. Maydica. 55 : 27-32.

Taye, G., Tarekegne, A. and Tanner, D.G. (2000). Estimation of optimum plot dimensions and replication number for wheat experimentation in Ethiopia. African Crop Sci. Jour. $8: 11-23$. 